\title{
METOdOLOGIAS DE ENSINO DE FÍSICA MODERNA E CONTEMPORÂNEA VOLTADAS PARA O ENSINO MÉDIO: INCOERÊNCIAS QUANTO A APLICABILIDADE
}

\section{ARTIGO DE REVISÃO}

DANTAS, Cícero Samuel Gonçalves ${ }^{1}$

DANTAS, Cícero Samuel Gonçalves. Metodologias de ensino de física moderna e contemporânea voltadas para o ensino médio: incoerências quanto a aplicabilidade. Revista Científica Multidisciplinar Núcleo do Conhecimento. Ano. 06, Ed. 12, Vol. 09, pp. 103-114. Dezembro de 2021. ISSN: 2448-0959, Link de acesso: https://www.nucleodoconhecimento.com.br/educacao/metodologias-de-ensino, DOI: 10.32749/nucleodoconhecimento.com.br/educacao/metodologias-de-ensino

\section{RESUMO}

A inserção de tópicos de Física Moderna e Contemporânea (FMC) nas escolas do Brasil, hoje, já é uma realidade nos livros didáticos voltados para o ensino médio (EM). Não basta apenas inserir tais conteúdos nos livros textos trabalhados pelos docentes em salas de aula, é preciso, além disso, analisar aspectos relevantes envolvidos no processo de ensino-aprendizagem que viabilizem um ensino significativo. Por meio de uma pesquisa de revisão bibliográfica o objetivo desse artigo é analisar as metodologias de ensino direcionadas ao ensino da FMC, observando as divergências ou incoerências no que concerne a aplicação no ensino médio, o qual, como é sabido, apresenta inúmeros problemas tanto de caráter curricular como estrutural. As análises mostraram que algumas metodologias implementadas fogem da realidade das escolas brasileiras, como o excesso de tópicos de FMC, contrapondo a quantidade de aulas destinadas a disciplina de Física.

\footnotetext{
${ }^{1}$ Mestre em Ensino de Física, pós-graduando em Engenharia de Controle e Automação Industrial, Licenciado em Física e Tecnólogo em Manutenção Industrial.
}

RC: 103891

Disponível em: https://www.nucleodoconhecimento.com.br/educacao/metodologiasde-ensino 
Palavras-chave: Revisão Bibliográfica, Metodologias de Ensino, Física Moderna e Contemporânea.

\section{INTRODUÇÃO}

Historicamente o estudo da Física é dividido em três grandes etapas: a Física clássica (FC); compreende os trabalhos desenvolvidos por Copérnico, Galileu e Newton; a Física Moderna; conjunto de teorias surgidas no início do século XX; e a Física Contemporânea [2] com início no final da segunda grande guerra cujo principal interesse são as partículas subatômicas (DOMINGUINI, 2012). Sendo assim, de modo geral, a Física Moderna e Contemporânea (FMC) surge no começo do século XX para modificar e complementar os conceitos da Física Clássica, tendo início com a hipótese de Max Planck (da quantização de energia) para resolver o problema do corpo negro. Em 1905, Albert Einstein publica artigos que tratam do efeito fotoelétrico, do quantum de luz, da relatividade restrita e do movimento browniano. No final de 1920 a estrutura teórica da Física Moderna se completa com os trabalhos de Schrodinger, de Broglie, Heisenberg e dentre outros (SALES et al., 2008).

Há várias razões para ensinar FMC no ensino médio. Uma delas é a grande quantidade de implicações tecnológicas (TORRE, 1998), pois o estudo da FMC possibilita aos estudantes uma leitura e interpretação da sociedade tecnológica atual, tornando os conhecimentos mais significativos para eles (GARCIA; LOCK, 2009). Exemplos de tecnologias disponíveis em nossa sociedade com base nos avanços da FMC, são os celulares, os tabletes e os computadores.

Ensinar FMC no ensino médio não é tarefa fácil, tanto do ponto de vista prático como teórico. Por isso, a abordagem dessa área da Física vem causando preocupação em pesquisadores e professores desde muito tempo (CARUSO; FREITAS, 2009). Para Gil et al. (1987), desde a década de 80, há o interesse de inserir conteúdos de Física Moderna no ensino médio. A partir de 2002 diversos tópicos sobre Física Moderna foram implementados no ensino médio, dentre os 
quais podemos citar: as Linhas Espectrais, Teoria da Relatividade, Partículas Elementares e Dualidade Onda-Partícula. Todos esses temas foram desenvolvidos por estudiosos da área, tanto do ensino superior quanto do ensino médio (PIETROCOLA E SABINO, 2016).

Para Garcia e Costa (2014) ensinar física é bastante complexo e, por isso, há grande dificuldade dos alunos nessa disciplina. Costa (2004) afirma que a Física é uma das disciplinas, se não a mais, que reprovam no ensino médio por conta da exigência de conhecimentos mínimos de álgebra, raciocínio logico e de um conjunto extenso de teorias científicas. Por conta dessa complicação que envolve o estudo da Física, muitos alunos acabam desmotivados e, além das reprovações, abandonando os estudos.

Embora seja imprescindível o estudo da FMC, sabe-se que existem diversos fatores que "impossibilitam" um efetivo ensino de FMC no ensino médio, tais como baixa carga horária da disciplina, em média duas aulas por semana de Física, falta de ambientes nas escolas que viabilizem a implementação de aulas exploratórias ou experimentais, além do excesso de conteúdo da própria FC. Então, é possível aplicar uma metodologia direcionada ao ensino da FMC em situações tão adversas?

O objetivo dessa pesquisa é analisar algumas metodologias de ensino publicadas em revistas do Brasil nos últimos 20 anos, retrocedendo a partir do início de 2020, observando as incoerências encontradas quanto a aplicabilidade no ensino médio no que concerne ao estudo de temas da Física Moderna e Contemporânea (FMC).

Foram selecionados 17 trabalho em revistas e analisadas entre os meses de maio e julho de 2020 para esta pesquisa, sendo elas: Caderno Brasileiro de Ensino de Física, da UFSC; Experiências em Ensino de Ciências, da UFMT; Física na Escola; Investigações em Ensino de Ciências, além dos dados disponíveis e selecionados no Google Acadêmico. A seleção dos trabalhos foi realizada usando-se a palavrachave "metodologia em Física Moderna e Contemporânea (FMC)" nos bancos de dados das fontes supracitadas.

RC: 103891

Disponível em: https://www.nucleodoconhecimento.com.br/educacao/metodologiasde-ensino 
Vale salientar, por último, que a quantidade de trabalhos encontrados foi muito grande. Sendo assim, a escolha dos artigos foi desagregada em função das metodologias cuja aplicabilidade estava mais próximo da realidade das escolas e, principalmente, dos alunos.

No próximo tópico é descrito as metodologias de ensino de FMC direcionadas ao ensino secundário.

\section{METODOLOGIAS DE ENSINO DE FÍSICA MODERNA E CONTEMPORÂNEA (FMC) PARA O ENSINO MÉDIO}

Dividiu-se esse tópico em duas partes: na primeira é discutido metodologias que abordam a Teoria da Relatividade Restrita (TRR) e a teoria quântica, especificamente. A segunda parte trata das metodologias de ensino para temas da Física Moderna e Contemporânea de modo geral.

\subsection{TEORIA QUÂNTICA E TEORIA DA RELATIVIDADE RESTRITA (TRR)}

A proposta do trabalho de Pietrocola e Sabino (2016) é investigar quais os saberes necessários que os professores devem possuir para que consigam inserir uma sequência de ensino voltada para temas de Física Moderna. Para tanto, utilizaram a análise qualitativa dos dados através de gravações das aulas sobre o Efeito Fotoelétrico, ministradas por professores da rede pública estadual de ensino. As atividades foram distribuídas em seis aulas cujos objetivos foram: simular o caráter investigativo, tal que os alunos relacionem a ocorrência do fenômeno; exibição, análise e discussão de um vídeo sobre o conceito de quantum e, resolução de questionário, além da leitura e interpretação de texto sobre o efeito fotoelétrico.

Os dois autores citados acima propõem uma metodologia de caráter inovador, fazendo com que os alunos sejam mais participativos e autônomos durante as aulas. Uma das dificuldades apontadas pelos autores foi a necessidade de uma melhor 
"preparação" dos saberes curriculares por parte dos docentes. Sendo assim, com base nessa informação, podemos concluir que a aplicação dessa metodologia de ensino requer uma preparação contínua dos professores sobre tópicos de FMC.

Usando um ambiente virtual de Física, Sales et al. (2008) discutem a aplicação de um Objeto de Aprendizagem (OA), chamado Pato Quântico, aplicando atividades exploratórias no cálculo da constante de Planck, usando, como referencial teórico, a teoria de aprendizagem significativa de David Ausubel [3]. O objetivo do OA é facilitar o entendimento do efeito fotoelétrico.

Usando o aparato experimental os professores possibilitam aos alunos, uma interação maior com o mundo físico e com novas situações-problemas dos fenômenos discutidos, por meio da modificação das variáveis durante a simulação, de maneira imediata, as quais não poderiam ser realizadas na prática concreta. $\mathrm{O}$ ensino por meio do OA revelou ser acessível ao ensino de alguns conceitos físicos, mostrando ser uma ferramenta aliada ao professor durante as situações didáticas em sala de aula.

Caruso e Freitas (2009) discutem a relatividade de Einstein em quadrinhos (tópicos como unificação do espaço-tempo, a relação massa-energia e a dilatação do tempo), ou seja, por intermédio de tirinhas tendo por base o trabalho de um aluno da Oficina de Educação através de Histórias em Quadrinhos e Tirinhas (ODUHQ [4]). Tal proposta mostra que essa linguagem auxilia os temas escolares (como a TRR). Ou seja, a ideia básica dessa metodologia é a ligação entre a Arte e a Física.

O interessante nesse projeto é que o aluno não engendra conhecimento, ele apenas traduz o conhecimento para a linguagem dos quadrinhos; desde que, é claro, o aluno compreenda o conteúdo estudado. Outro ponto positivo nessa abordagem é o fato de as tirinhas ser facilmente desenvolvidas em sala de aula e, evidentemente, manter a originalidade. Os autores afirmam que o uso de tirinhas pode auxiliar o professor a estimular os alunos a reflexão prévia de um dado conteúdo (CARUSO; FREITAS, 2009). 
A metodologia baseada em histórias de quadrinhos, além da interdisciplinaridade, possibilita o desenvolvimento da criatividade e da imaginação dos alunos. No entanto, muitos professores as usam apenas como meio ilustrativo em suas aulas (CARUSO; FREITAS, 2009).

Por intermédio de uma abordagem histórica, Wolf e Mors (2006), tratam conceitos da Teoria da Relatividade Restrita (TRR) no ensino médio, tanto em escolas particulares quanto em públicas. O material didático produzido pelos autores possui dois textos: o primeiro é voltado para o professor e o outro para os alunos. No material dos alunos os autores focam dois aspectos; um histórico e outro conceitual. Já o material do professor procura apoiá-lo no ensino da abordagem dos conceitos da TRR, destacando desde o pensamento de Aristóteles (visão empirista), passando pelo trabalho de Galileu até chegar na TRR de Einstein.

Vale destacar que a aceitação do tema por parte dos alunos foi um dos principais resultados encontrados pelos autores na abordagem histórica, pois aqueles não estavam acostumados com essa metodologia em sala de aula.

Cavalcante; Tavolaro e Haag (2005) apresentam diversas propostas experimentais para o estudo de espectros de emissão e absorção, além de uma proposta com materiais de baixo custo para observação de espectro de absorção. Através de um espectroscópio manual os autores obtiveram os espectros de uma lâmpada de mercúrio $(\mathrm{Hg})$ comercial e de um LED (semicondutor) vermelho com o intuito de comparar com os demais métodos abordados por eles.

Usando um enfoque construtivista, Silva e Rodrigues (2013) analisam quatro abordagens metodológicas diferentes sobre o efeito fotoelétrico, e como aquelas influenciam os educandos do ensino médio. As estratégias usadas foram: história da Ciência (HC); ciência, Tecnologia e Sociedade (CTS); experimentos concretos e explicação do fenômeno através de aulas expositivas. 


\subsection{FÍSICA MODERNA E CONTEMPORÂNEA (FMC)}

O trabalho de Moreira e Osterman (2000) é uma revisão bibliográfica na área de Física Moderna e Contemporânea (FMC). Questões metodológicas (grifo nosso), epistemológicas, históricas, estratégias de ensino no campo da FMC são o foco do trabalho daqueles autores. Em suas conclusões, duas dificuldades para implementar os temas de FMC no ensino médio são identificadas: a primeira é qual(is) tema(s) deve(m) ser inserido(s) no currículo escolar; e o segundo como colocar tais temas.

O trabalho de Garcia e Lock (2009) analisa trabalhos desenvolvidos para inserção da Física Moderna e Contemporânea no ensino médio, tais como a Teoria da Relatividade (TR), Mecânica Quântica, Física de Partículas e Supercondutividade. Analisando os resultados, os autores concluíram que existem poucas propostas de ensino voltadas para algumas áreas da FMC, tais como a Física de Partículas (grifo nosso).

Usando a teoria da aprendizagem significativa, Garcia e Costa (2014) propõem uma abordagem metodológica para inserção da FMC no ensino médio, através de práticas experimentais e aplicações na Astronomia. O material didático com 6 unidades de ensino é formado por 16 atividades divididas em 39 aulas nas quais foram trabalhadas leituras, discussões de artigos científicos, experimentos, vídeos e simuladores da internet. Cada unidade de ensino apresenta atividades propostas. $\mathrm{Na}$ unidade dois, por exemplo, os alunos realizaram um experimento cujo objetivo foi medir a espessura de um fio de cabelo usando-se um feixe de luz (laser).

Os autores (GARCIA E COSTA, 2014) aplicaram um pré-teste para diagnosticar os conhecimentos prévios dos alunos sobre os temas propostos. Verificou-se, após a aplicação do pré-teste, que os alunos não apresentavam nenhum conhecimento prévio; praticamente nulo. No entanto, após as atividades, ou seja, pós-teste, os autores verificaram que os resultados foram convincentes, relativamente ao préteste. A proposta metodológica deixou as aulas mais dinâmicas, os alunos mais participativos e interessados por elas. 
O projeto de Cavalcante e Tavolaro (2001) permite a inserção da FMC, mais especificamente o estudo do comportamento dual da luz, no ensino médio através de oficinas, usando materiais de baixo custo. As oficinas são divididas em duas partes: na primeira os autores mostram experimentos que comprovam a natureza ondulatória da luz por meio da interferência e da difração, fenômenos típicos de ondas. Na segunda parte, para evidenciar o comportamento corpuscular da luz, os autores realizaram experimentos em que se observe a transformação de energia luminosa em energia elétrica. Ou seja, o efeito fotoelétrico. Além dos experimentos concretos, eles também usaram softwares disponíveis na internet para investigar a dependência da energia cinética dos elétrons emitidos com a frequência da luz emitida na remoção dos elétrons.

Parisoto; Moreira e Almeida (2017) divulga uma proposta de ensinar conceitos de Eletromagnetismo, Óptica, Ondas e FMC no contexto da área da Medicina, usando a teoria de aprendizagem significativa de David Ausubel como referencial teórico. Integram a proposta as aplicações médicas, tais como: ultrassonografia, funcionamento do olho humano, funcionamento da radiografia, mamografia, Ressonância Magnética Nuclear (RMN), Medicina Nuclear (MC) e a Tomografia Computadorizada (TC). A estrutura da proposta foi dividida em cinco encontros (de $10 \mathrm{~h} /$ aula) cujas estratégias usadas pelos autores foram, dentre outras: organizadores prévios, modelagem computacional, simulações e construção de mapas conceituais.

Oliveira; Vianna e Gerbassi (2007) realizaram uma pesquisa qualitativa com professores do ensino médio cujo objetivo foi saber a opinião deles sobre a introdução de tópicos de FMC (especificamente os Raios-X) no ensino secundário. O trabalho serviu de base para a construção de uma proposta metodológica onde o tema selecionado foi contemplado numa perspectiva CTS (Ciência, Tecnologia e Sociedade).

A proposta de ensino de Costa (2004) permite trabalhar conceitos de FMC com instrumentos simples do dia a dia, pois muitos fenômenos da natureza podem ser 
estudados através de experimentos e estes são a base para o entendimento de tópicos (a lei do deslocamento de Wien, por exemplo) de FMC. Além da realização de experimentos com materiais concretos 0 autor propõe experimentos virtuais (simulações) tais como a do efeito fotoelétrico.

\section{CONSIDERAÇÕES FINAIS}

Atualmente é imprescindível inserir tópicos de FMC no currículo escolar; não só no currículo do ensino médio, mas também no do ensino fundamental. No entanto, percebeu-se nas metodologias aqui analisadas certas incoerências para a inserção efetiva de temas de FMC no ensino médio. A primeira diz respeito a preocupação dos autores apenas em inserir temas de FMC no ensino médio, esquecendo outros aspectos relevantes envolvidos no contexto escolar, pois não basta apenas inserir no currículo temas de FMC, é preciso que os alunos aprendam significativamente (em princípio) o conteúdo programado e ministrado em sala de aula desde tópicos da FC.

A proposta de Parisoto; Moreira e Almeida (2017), embora seja bastante interessante em muitos aspectos, apresenta excesso de tópicos selecionados pelos autores, os quais ultrapassam a carga horária de aulas de física nas escolas do Brasil, em geral, são duas aulas de 50 minutos por semana, para sua efetiva implementação. Eis a pergunta, então: é possível aplicar uma metodologia direcionada ao ensino da FMC em situações tão adversas? A resposta é "não", pois as escolas visam apenas a aprovação dos alunos em exames e provas externas, "objetivando" apenas a memorização de conteúdos para a aprovação daqueles. A quantidade de temas em função da carga horária, portanto, daquela metodologia de ensino é inconsistente para a realidade (hoje) da maioria das escolas brasileiras.

Segundo Costa (2004) os experimentos na área de FMC possibilitam aos alunos uma maior interação com os fenômenos estudados. Porém, a quantidade de temas propostos em sua metodologia é elevada, o que a torna inconsistente devido à quantidade ínfima de aulas de Física no ensino médio em nosso país. 
Por outro lado, uma das metodologias, a utilização de oficinas experimentais, que mais se aproximam da realidade das escolas brasileiras, quanto a questão do custo é a de Cavalcante e Tavolaro (2001), pois os autores optam pelo uso de materiais do cotidiano dos alunos, facilitando, dessa forma, a aprendizagem de temas de FMC no ensino médio.

\section{CONCLUSÃO}

Com base nas análises feitas sobre os trabalhos aqui descritos e com base no currículo e nos problemas estruturais do ambiente escolar, percebe-se que a melhor forma de inserir novas metodologias sobre algum tópico de FMC é ao longo do curso de Física ao longo dos livros textos, não apenas no terceiro ano, mas sim desde os anos iniciais em que a disciplina de Física é inserida no currículo escolar. Ou seja, ao abordar o movimento de corpos no curso de mecânica no ensino fundamental ou médio é possível que o docente trabalhe, (paralelamente, a relatividade do tempo e a contração do espaço (teoria da relatividade de Einstein), usando, sempre que possível, a metodologia que mais se adéque a realidade da turma, tanto em nível cognitivo quanto material. Outro exemplo seria em relação à estrutura atômica da matéria (início do curso de eletricidade, terceiro ano do ensino médio): o professor pode, portanto, introduzir o conceito de antimatéria paralelamente aquele. Em suma: para cada tópico de Física Clássica o professor pode, sem nenhuma perda, inserir temas correspondentes/complementares da FMC para aquele tópico trabalhado, optando sempre por metodologias que contemplem o uso de materiais de fácil acesso aos estudantes.

\section{REFERÊNCIAS}

CARUSO, F; FREITAS, N. Física moderna no ensino médio: o espaço-tempo de Einstein em tirinhas. Caderno Brasileiro em Ensino de Física. v. 26, n.2: p.355366, 2009. 
CAVALCANTE. M. A; TAVOLARO, C.R.C. Uma Oficina de Física Moderna que Vise a Sua Inserção no Ensino Médio. Caderno Catarinense de Ensino de Física. v. 18, n. 3, 2001.

CAVAlCANTE, M. A; TAVOLARIO, C. R. C; HAAG, R. Experiências em Física Moderna. Física na Escola. v. 6, n. 1, 2005.

CostA, A. G. C. Como Ensinar Física Moderna no Ensino Médio: Discussões e Sugestões.

http://www.infis.ufu.br/infis_sys/pdf/ANDRE\%20GUSTAVO\%20CRUZ\%20DA\%20CO STA.pdf/ Acesso em: 21 de Julho de 2020.

COSTA, M; GARCIA, L.C. Inserção de Física Moderna no Ensino Médio por Meios de Práticas Experimentais e Aplicações na Astronomia. Os Desafios da Escola Pública Paranaense na Perspectiva do Professor PDE. Versão Online, 2014.

DOMINGUINI, L. Física Moderna no Ensino Médio: com a Palavra os Autores dos Livros Didáticos do PNLEM. Revista Brasileira de Ensino de Física. v. 34, n. 2, 2502, 2012.

GARCIA, Elias. Pesquisa bibliográfica versus revisão bibliográfica - Uma Discussão Necessária. Revista Língua \& Letras. v. 17, n. 35, 2016.

GIL, D. P.; Senent, F. \& Solbes, J. (1987). La Introducción a La Física Moderna: Un Ejemplo Paradigmático de Cambio Conceptual. Enseñanza de las Ciencias, Barcelona, (n. Extra), p. 209-210.

LOCH, J; GARCIA, N.M.D. Física moderna e contemporânea na sala de aula do ensino médio. Encontro Nacional de Pesquisas em Educação em Ciências, 2009.

RC: 103891

Disponível em: https://www.nucleodoconhecimento.com.br/educacao/metodologiasde-ensino 
MOREIRA, M. A; OSTERMAN, F. Uma revisão bibliográfica sobre a área de pesquisa "física modera e contemporânea no ensino médio". Investigação em Ensino de Ciências, v. 5(1), pp. 23-48, 2000.

MORS, P.M; WOLF, J.F.S. Relatividade no Ensino Médio: Uma Experiência com Motivação na História. Experiências em Ensino de Ciências, v1(1), pp. 14-22, 2006.

OLIVEIRA, F. F; VIANNA, D.M; GERBASSI, R.S. Física Moderna no Ensino Médio: O Que Dizem os Professores. Revista Brasileira de Ensino de Física. v. 29, n. 3. p. 447-454, 2017.

PARISOTO, M. F; MOREIRA, M.A; ALMEIDA, W. D. O Ensino de Conceitos de Eletromagnetismo, Óptica, Ondas, e Física Moderna e Contemporânea Através de Situações que Envolvem Equipamento Tecnológicos de Medicina. Física na Escola. v. 15, n. 1, 2017.

SABINO, A.R; PITROCOLA, M. Saberes Docentes Desenvolvidos por Professores do Ensino Médio: Um Estudo de Caso com a Inserção da Física Moderna. Investigação em Ensino de Ciências, 2016.

SALES, G. L et. al. Atividades de Modelagem Exploratória Aplicada ao Ensino de Física Moderna com a Utilização do Objeto de Aprendizagem Pato Quântico. Revista Brasileira de Ensino de Física, v. 30, n. 3, 2008.

SILVA, N. P; RODRIGUES, M. I. R. Física Moderna no Ensino Médio: O Efeito Fotoelétrico Sob Quatro Diferentes Abordagens Didáticas. Disponível em: https://www.researchgate.net/publication/268685896_FISICA_MODERNA_NO_ENSI NO_MEDIO_O_EFEITO_FOTOELETRICO_SOB_QUATRO_DIFERENTES_ABORD AGENS_DIDATICAS/ Acesso em: 24 de Julho de 2020.

TORRE, A.C. de la, Reflexiones Sobre la Enseñanza de la Física Moderna. Educación en Ciencias, v. II, n. 1, p. 79-90, 1998. 


\section{APÊNDICE - REFERÊNCIA NOTA DE RODAPÉ}

2. Por Física Moderna e Contemporânea queremos dizer todo o conhecimento científico desenvolvido na área da Física desde o início do século XX até os dias de hoje.

3. David Ausubel (1918-2008) foi um pesquisador norte-americano que desenvolveu o conceito de subsunçor (conhecimento prévio). Para ele, quanto mais o ser humano sabe, mais ele aprende. Para mais informações, veja $<$ https://novaescola.org.br/conteudo/262/david-ausubel-e-a-aprendizagemsignificativa>. Acesso: 13/07/2020.

4. Disponível em: <www.cbpf.br/eduhq>. Acesso: 25/06/2020.

Enviado: Março, 2021.

Aprovado: Dezembro, 2021. 